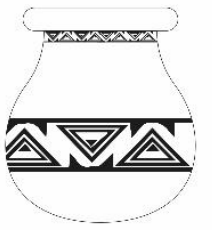

\title{
“A ONDA": UMA ANÁLISE FÍLMICA SOBRE AS FORMAS DE PODER E A EDUCAÇÃO
}

\author{
Pamela Cristina Ribeiro da Silva ${ }^{1}$ \\ Parsifal André da Silva ${ }^{2}$
}

Resumo: O presente artigo, resultado de pesquisa bibliográfica, tem como finalidade demonstrar o cinema como choque da realidade e como uma ferramenta filosófica, e não apenas como entretenimento, possibilitando a contribuição não linguística para o pensamento em detrimento à realidade. Por conseguinte, analisando as formas de poderes no âmbito social e escolar em uma relação de microfísica do poder difundida no processo educacional. Além de ressaltar a ambiguidade do papel da educação, onde a mesma pode ser ao mesmo tempo libertadora e propagadora de ideologias, no olhar acrítico sobre sua realidade social e de alienação durante o processo de formação do sujeito.

Palavras-Chave: Cinema; Educação; Filosofia; Relações de Poder.

\footnotetext{
${ }^{1}$ Discente do curso de licenciatura plena em filosofia da Universidade do Estado do Pará e bolsista voluntaria PIBIC.

${ }^{2}$ Discente do curso de Licenciatura Plena em Filosofia da Universidade do estado do Pará.
} 


\section{Introdução}

O artigo tem a sua importância por analisar e criticar através da arte como a educação pode ser ambígua, ao mesmo tempo em que ela pode ser libertadora, propagadoras de ideologias e do poder do Estado, sem falar também dar um novo papel para as artes, no caso aqui do trabalho o cinema, e demonstrar que elas só não servem para entreter, e sim também um meio de levantar debates, aprofundar temas e por que não dizer um modo de filosofar. Além de atribuir o cinema como uma forma de contribuição e exposição não lingüística para o pensamento em detrimento a realidade.

\section{Sinopse do filme}

O filme a "Onda" foi lançado em 21 de agosto de 2009, com a direção de Dennis Gansel. As filmagens se passam em na Alemanha, em uma escola, onde os discentes precisam escolher entre a disciplina da autocracia e a outra é a anarquia. Já o professor Rainer Wenger (Jurgen Vogel) é colocado para dá aulas de autocracia, cuja disciplina não é a qual gostaria de ministrar, durante a aula e em debate com a sala o professor decide aplicar uma metodologia, na tentativa de ampliar o conhecimento e exemplificação sobre o conteúdo da disciplina.

Nessa relação de professor e alunos é aplicada uma forma de governo fascista, onde são denominadas as regras internas, as formas de comportamento e denominação "A Onda", tendo para identificação do mesmo uma blusa branca e uma saudação que faz referencia a um movimento de uma onda. Contudo, tal relação e movimento passam a ultrapassar as barreiras da escola e se propagar no âmbito social, saindo de fora do controle do professor. Os acontecimentos se tornam sérios e o professor Wenger tenta resolver à proporção que o movimento tomou. Só que a experiência levada muito a sério, provocando sérias consequências tanto na vida do professor quanto na vida dos alunos.

\section{A relação do Cinema e Filosofia}

O cinema possibilita aspectos ficcionais para levar os indivíduos a diferentes maneiras e perspectivas para tratar de diversos assuntos que direcionam o expectador a vários campos estudados pela filosofia, sociologia, psicologia e entre outros. Interligando a imagem, a linguagem, o som e o movimento que perpassa aspectos tratados em sociedade e pelo 
individuo como: os acontecimentos históricos, de vida, os fatos sociais, sobre a morte, a liberdade, a violência, o amor e entre outros que contornam as profundidades humanas.

A reflexão filosófica advém da utilidade de aprofundamento dos diversos objetos onde detém a compreensão crítica, com valores estéticos e cognitivos. Buscando a compreensão do mundo que o cerca e sobre si mesmo.

O cinema possibilita aspectos ficcionais para levar os indivíduos a diferentes maneiras e perspectivas para tratar de diversos assuntos que direcionam o expectador a vários campos estudados pela filosofia, sociologia, psicologia e entre outros. Interligando a imagem, a linguagem, o som e o movimento que perpassa aspectos tratados em sociedade e pelo individuo como: os acontecimentos históricos, de vida, os fatos sociais, sobre a morte, a liberdade, a violência, o amor e entre outros que contornam as profundidades humanas.

A reflexão filosófica advém da utilidade de aprofundamento dos diversos objetos onde detém a compreensão crítica, com valores estéticos e cognitivos. Buscando a compreensão do mundo que o cerca e sobre si mesmo no cinema, assim como qualquer outra forma de arte, seja ela a literatura, as pinturas, ou qualquer manifestação artística, ela pode ser o nosso meio para descrever a nossa realidade por meio da expressão corporal, do visual, do linguístico, que interpretar através de imagens, de palavras e do corpo a vida na qual estamos inserindo em uma relação que se pode ter e ser usado no ensino-aprendizagem. E nesse sentido, o cinema pode ser a arte do real, no sentido de abordar questões do nosso cotidiano, levantando temas de modo ficcional ou baseados em uma realidade de algum individuo, promovendo a atuação do olhar na reflexão sobre os mesmos.

Com isso, nós indagando e debatendo sobre determinado assunto tratados, fazendo-nos despertar da mesma forma que o homem se libertou da caverna do Platão e sair em busca de conhecimento, norteando o cinema não como uma mera maneira de diversão diante do meio social, mas captando através das imagens as mensagens que nos levam a um choque com a realidade.

Todavia, para o cinema ganhar um caráter filosófico ele precisa elaborar conceitos, seguindo os mesmo princípios de Deleuze e Gattari, que dizem que a filosofia é na verdade elaboração de conceitos (1997). Consequente, estaríamos elevando os diretores de cinema para o patamar de pensadores sobre como impulsionar a interrogação e exaltação dessa arte por meio da imagem em alguns aspectos que sua atenção se concentre no assunto tratado na história, onde afinal a arte é um meio de nos provocar a pensar também.

Contudo, ele também pode ser um reprodutor de teses estudadas na filosofia, ressaltando pontos significantes da construção humana em sua racionalidade e sentimentais 
explorados em filme, como por exemplo; O sétimo selo (1956) na qual aborda a angústia do ser humano diante dos enigmas da natureza inspirada no pensamento filosófico do filosofo nórdico Soren Kierkegaard.

\section{A educação e as relações de poder}

E conduzindo ao filme "A Onda" (Die Welle, no original alemão) dirigido pelo alemão Dennis Gansel que tem no currículo os filmes "Napola" e "Das Phantom", ambas tem como plano de fundo da história o regime Nazista e suas influencias no destino dos personagens. "A Onda" tem a seguinte historia de um professor que vai ministrar um curso durante uma semana sobre autocracia, e para ministrar esse curso ele propõe uma dinâmica para mostrar de forma mais interessante o assunto. A partir daí, como podemos fazer uma relação entre educação e Poder, como processo do cidadão do filme? Primeiro faremos uma definição do que seja educação. A educação pode ser as atitudes e/ou disposições fundamentais, não só intelectuais, mas também podem ser emocionais do homem para com si e com a natureza (TEIXEIRA, 1959).

A educação estaria interligada no desenvolvimento do caráter e dos princípios morais em cada ser humano. Mas, esse processo no seio social advém, por sua vez, de educações que perpassam por várias diretrizes humanas, seja ela na instituição escolar, em casa com os pais, nas igrejas, na comunidade e esse direcionamento está interligado com o direcionamento da personalidade do sujeito após que é inserido em sociedade. Agregando com elas um caminho de mão dupla, onde o conhecimento pode ajudar a desenvolver indivíduos críticos e pensantes sobre seu meio ou eleva-los a condições que impulsionam ao olhar da alienação e a ação acrítica sobre suas relações sociais.

Já na relação entre poder e educação é visibilizada em vários reflexos, desde a relação do professor e aluno quanto aluno para aluno, onde em algumas ocasiões houve a utilização do conhecimento para manipular e alienar pessoas, conquistarem e manter-se no poder. Um exemplo que podemos tirar no período que a Alemanha viveu sobre o período nazista, onde as escolas foram "nazificadas", tendo professores que eram defensores ou membros do partido nazista fazendo com que a educação fosse um instrumento de propagação idealista da sua época.

Nesse caso utilizarei a definição de poder que o filósofo francês Michel Foucault que acredita que o poder é algo que circula e que funciona em cadeia, nunca estaciona em um lugar fixo, mas sim funciona e exerce em suas múltiplas faces (1997). Ou seja, o poder não 
está apenas nas mãos do estado, mas sim dispersada em varias instituições, inclusive as escolas. A escola também é uma instituição onde ocorre as relações de poder.

E a escola como sendo instituição poderia ser carregada nesse sentido: estrutura material e humana que serve à realização de ações de interesse social ou coletivo; organização, daí entra a relação de poder, onde uma ideologia pode definir e influenciar todo o sistema pedagógico da escola, fazendo que os alunos sofressem tal influencia. Como no exemplo citado do período nazista anteriormente. Nesse, sendo o poder um fio de rede, podemos encontrar nas escolas ideologias do estado presente na educação, pois "o Estado reconfigura todo esse complexo tecido social, reconstituindo a dinâmica de indivíduos, grupos e classes a partir da constrição da forma" (MASCARO, p.65, 2013).

Partindo esses dois conceitos, como podemos vê no filme? A partir da didática do professor, na qual é eleito pela turma para ser uma espécie de líder de um grupo que tem o nome escolhido como "A Onda", curiosamente o mesmo nome do título. O poder que ele ganha ao ser líder como a interferir no comportamento dos alunos dentro e fora de sala. E os alunos que fazem parte da "geração que passa rapidamente alcança de todo o saber humano, somente aquilo de que ela precisa" (SCHOPENHAUER, P.29, 2005) são os que mais sofrem influências do professor Wenger.

Uma clara exemplificação do filme dessa influencia do professor, podemos citar o personagem Tim, que durante o filme leva a sério tudo o que professor fala durante as aulas, chegando a mencionar com os seus pais na empolgação do que aprendeu durante as aulas e fazendo o que o professor Wenger falava, queima as suas roupas de marca, marcha como se fosse um soldado, obedecendo as ordens do professor sem ao menos perguntar o por quê, são alguns exemplos dessa dominação e fatores psicológicos que vão desencadear no personagem do Tim por sofrer a ausência de seus pais no seu desenvolvimento pessoal.

A educação que deveria ser uma forma de expressão própria do ser humano, um desenvolvimento intelectual autônomo, ganha traços de uma mera reprodução aos olhos do personagem Tim. Coincidentemente, no filme, na didática proposta pelo professor Wenger para melhor explicar o que seria a forma de governo da autocracia, propõem uma didática. Nessa didática eles formam na sala uma espécie de governo autocrático na qual o professor é o líder, e eles têm como base o modelo de governo nazista. E assim, esses estudantes, como dizia o filósofo Schopenhauer (2005), são aqueles tipos de estudantes ou estudiosos que só tem mira apenas na informação, não na instrução.

A educação pode ser alienante a partir de que o professor apenas reproduz o conhecimento e fazendo com que os seus alunos sejam apenas reprodutores do conhecimento, 
sem provocar questionamentos ou o professor não permite que se questione o que estiver passando, já que alguns docentes podem direcionar seus olhares visando: “cada um pensa somete nos seus benefícios próprios" (SCHOPENHAUER, p.28.2005), como diria o filosofo. E assim, quando um aluno questiona o professor procura ao máximo evitar que ela não tenha voz. No filme temos o exemplo da personagem Karo que sempre é a questionado, mas chega um momento que ela é ignorada, pelo fato de ser a única de vermelha em meio a multidão de alunos usando brancos. Pois como o próprio Foucault mesmo afirmava (1997) onde havia poder havia resistência e essa resistência pode se da de forma nem sempre violenta.

Nesse caso, o professor quer ser o autônomo, ser o autoritário, impregnar na cabeça dos alunos só aquilo que ele acredita o que é certo, sem dá chance de questionamento ou levantar o mesmo. Assim, educando os alunos a serem reprodutores de ideias, possivelmente manipulados pelas ideias de seu educando sem ao menos levantar possíveis refutações dentro das salas de aulas ou fora delas. Permitindo a reprodução de um sistema alienante pela qual podem exercer suas perspectivas que serão um direcionamento para se manter a ordem e o poder, servindo de reprodução social.

\section{Conclusão}

Os desdobramentos vinculados à sétima arte demonstram que circundam as perspectivas interligadas a prática filosófica, perpassando por um víeis de ensino e aprendizado na relação de cinema e filosofia na teoria e tanto na sua reflexão, onde se faz um vasto campo de analises que podem vincular-se com teorias de muitos pensadores, observando tanto através da imagem em movimento. De modo a ressaltar que o cinema é uma ferramenta para a filosofia e que este se entrelaça a questões levantas na sociedade e no ser humano em relação a sua humanidade no retorno a si.

No olhar da educação se faz presente o caráter dual do mesmo que visa no seu papel à formação de novos cidadãos, mas tal prática de domesticação da racionalidade no desenvolvimento do processo cognitivo acaba por criar disparidades no âmago das mentes que, por vezes, mergulham nos problemas dos fatos sociais, quando não é criado um ambiente próprio para o desenvolvimento das indagações se tornam reprodutores do conhecimento e acabam deixando de lado a visão dos questionamentos, das refutações para aquilo que se busca enquanto verdade.

Tornando assim seres acríticos dentro dos alcances educacionais, aprisionando mentes que podem agir de maneira etnocêntrica sobre os outros indivíduos em sociedade e assim acabarem por enaltecerem as relações de poderes que se refletem, por vezes, nos 
comportamentos humanos. Exercendo em níveis variados nas inter-relações e não necessariamente e unicamente com o Estado, podendo enraizar na dominação de classes e refletindo nas educações sociais, educacionais, onde acabam por transformar pessoas dóceis politicamente e por meio da disciplina podem buscar controlar o ser humano e suas ações.

Portanto, o filme a "A Onda" é um filme repleto de observações e assuntos que se interliga na filosofia, visando inúmeras maneiras de se pensar sobre os nossos comportamentos, nossas ações, as formas de poder e suas implicações no âmbito educacional no choque com a realidade através da imagem.

\section{REFERÊNCIAS BIBLIOGRÁFICAS}

DELEUZE, G. \& GUATTARI, F. O que é a filosofia? Trad. Bento Prado Jr. E Alberto Alonso Muñoz. Editora 34, 1997 ( $2^{\circ}$ edição brasileira).

FOUCAULT, Michel. Microfísica do Poder. 11ª ed., Rio de Janeiro: Graal, 1997.

GUIMARÃES, Joana Regina Dutra; HEIJMANS, Rosemary Dore. "Analise do filme 'A Onda"”. Projeto "Tecnologias da informação: Cinema e educação”. Universidade Federal de Minas Gerais, MG. Setembro de 2013.

MASCARO, Alysson Leandro. Estado e forma política. São Paulo, SP: Boitempo, 2013.

ONDA, A. Direção: Dennis Gansel. Produzido por: Anita Schneider, Christian Becker e Nina Maag. Alemanha. 107 minutos. Som, cor. 2008.

PARANHOS, Flavio. $O$ filósofo de Brooklyn. Disponível em: http://filosofiacienciaevida.uol.com.br/ESFI/Edicoes/21/artigo77283-2.asp. Acessado em: 09 de agosto de 2016.

SCHOPENHAUER, Arthur. A arte de escrever. Tradução, organização, prefacio e notas de Pedro Süssekind. Porto Alegre: L\&PM, 2005. .

UNITED STATES HOLOCAUST MEMORIAL MUSEUM. Doutrinando a juventude. Disponível em: http://pt.slideshare.net/itqturma201/como-colocar-as-referncias-segundo-aabnt. Acesso em: 08 de agosto de 2016.

TEIXEIRA, Anísio. Filosofia e educação. Revista Brasileira de Estudos Pedagógicos. Rio de Janeiro, v.32, n.75, jul./set. p.14-27, 1959. 